\title{
Analytic Hierarchy Process (AHP) Approach To Aircraft Type Selection On High-Frequency Domestic Routes
}

\author{
Astrid Kartika, Alberto Daniel Hanani
}

\begin{abstract}
In opening a new route, all airline companies in Indonesia need to get approval from the Ministry of the Transportation Republic of Indonesia. When asking an approval to open a new route, it becomes an important thing and needs careful planning. The national flag carrier of Indonesia, which serves a full-service product to its customers, has plans to open several new domestic and international routes in 2019. Like other Indonesian airlines, it also needs to submit its five-year business plan to get the Air Transport Business Permit (or Surat Izin Usaha Angkutan Udara - SIUAU) from Ministry of Transportation. This paper focuses on several high-frequency domestic routes from/ to Soekarno Hatta International Airport, such as Jakarta - Denpasar, Jakarta - Medan, Jakarta Semarang, Jakarta - Surabaya, and Jakarta - Yogyakarta. By using both a combination of the Focus Group Discussion (FGD) and the Analytic Hierarchy Process (AHP) methods in selecting the most suitable aircraft type, several criteria and alternatives were defined. 6 (six) important criteria in selecting the most suitable aircraft (Maximum Take Off Weight (MTOW), Cost per Available Seat Kilometer (CASK), operational performance, delivery time, fleet commonality, and additional benefits) and 4 (four) alternative aircraft types (B737-800NG, B737-8MAX, CRJ1000, and A330-300) that are suitable for those routes were defined. The result shows that the most suitable aircraft for highfrequency domestic routes is B737-800NG, which rank first in fleet commonality, operational performance, and delivery time. Then followed by B737-8MAX, A330-300, and CRJ1000. Thus, this study provides an illustration of aircraft type selection problem solving for known routes, which expectedly could help other airline companies in considering more careful planning in the future.
\end{abstract}

Index Terms: Aircraft Selection Process, Analytic Hierarchy Process, Fleet Planning, Focus Group Discussion

\section{INTRODUCTION}

Even though the profitability of the airline industry has always been characterized by thin margins and cyclicality [1], otherwise the industry's trend is still improving every year. The fact shows the increasing number of revenues in most categories, such as passenger revenue and other revenue, which results in the total increase of $26 \%$ from total revenue between 2010 and 2015 [1]. In addition, the International Air Transport Association (IATA) also predicts an approximately $3.5 \%$ compound annual rate for

Revised Manuscript Received on April 19, 2019.

Astrid Kartika, Department of Management, Universitas Indonesia, Jakarta, Indonesia.

Alberto Daniel Hanani, Department of Management, Universitas Indonesia, Jakarta, Indonesia. the next 2 (two) decades, with an estimation of 8.2 billion air travelers at the end of 2037 [2].

Referring to CAPA's data, the number of visitors that come to Indonesia was significantly increased for the recent 10 years, from $6,323,730$ passengers in 2009 to $15,806,200$ at the end of 2018. The was a significant increase from 2016 to 2017 , reaching the $21.16 \%$ increase of total visitor arrival growth. This condition was affected by the increasing number of China tourists to Sam Ratulangi International Airport and Bali, also the government's effort in promoting other tourism areas, besides Bali [3]. On the other hand, from 2017 to 2018, the visitor arrivals growth was decreasing to $12,6 \%$ that is also still considered as a positive growth even though not as high as the previous year.

The national flag carrier of Indonesia, which serves a fullservice product to its customers, operates in both domestic and international flights. Until the end of 2018, it serves flights to 69 domestic destinations and 22 international destinations, including 110 domestic routes and 40 international routes. By June 2018, the national flag carrier of Indonesia serves approximately more than 600 daily flights and a fleet of 142 aircraft. The airline serves 3 continents Asia, Europe, and Australia, to several international destinations such as Japan, Malaysia, China Hong Kong, Korea, Amsterdam, and London. In 2019, it has plans to open several new domestic and international routes. For example, new destinations to 10 New Bali, which supporting Indonesia's Ministry of Tourism program, and several international routes, such as Nagoya (Japan), Jinan (China), Shenyang (China), Manila, Saigon, and Istanbul (Turkey). This study focuses on the domestic route, specifically focus on the 5 (five) highest frequency routes (Jakarta - Denpasar, Jakarta - Medan, Jakarta - Semarang, Jakarta - Surabaya, and Jakarta - Yogyakarta), which is the most important route that needs more careful planning to avoid financial loss.

In opening a new route, all airline companies in Indonesia needs to get approval from the Ministry of the Transportation Republic of Indonesia. The national flag carrier of Indonesia, like other airlines, also needs to submit its five-year business plan, which includes the market projection, financial projection, production calculation, and new route's profit and loss analysis. If the business plan is 
feasible enough, then the company could get Air Transport Business Permit (or Surat Izin Usaha Angkutan Udara SIUAU) from Ministry of Transportation. After that, then the airline company could continue to the next steps, which are submitting other files to get flight approval from Ministry of Transportation to and getting slot time from Indonesia Airport Slot Management (IASM).

When asking an approval to open a new route, it becomes an important thing and needs careful planning. The fleet planning for the airline industry is not different from other industries' planning activity, which is related to complexity, dilemmas, and uncertainty [4]. Reference [5] shows that the most important airline planning process is mostly categorized as follow Fleet Planning (includes the fleet type to acquire, the time, and number of fleet), Route Planning (includes choosing the route destination that is profitable and the availability constraints), and Schedule Development (includes the frequency number, the times of each route that the flights should be operated, also operational and fleet limitations).

Reference [4] shows that the key decision criteria in fleet sometimes highly sensitive to timing or the aircraft's availability, then sometimes becoming less contingent upon technology, and the decision sometimes also governed or affected by external factors, such as regulations, environment, and geography. Thus, it is very difficult to fix a permanent set of decision criteria. In helping to fix the set of key decision criteria, the key buying factors of airlines could help in establishing the aircraft design objective and providing economic and operational targets for airlines and manufacturers. Key buying factors in Asia was dominated by economics factor, then it is followed by aircrafts' performance factor, comfortability, the market and infrastructure, fleet commonality, and the last is the environment factor [4].

Other than key buying factors, the aircraft-specific selection criteria also could also help in deciding the decision criteria. For instance, the must-have aircraft selection criteria for lessors are the generous pricing from supplier, retains value, low reconfiguration costs, and a high degree of component standardization. Meanwhile, the musthave aircraft selection criteria for a short-haul scheduled carrier are delivered optimum economic value, competitive passenger appeal, ability to differentiate in the cabin, excellent customer perception, and containerized freight and baggage [4].

The airline structures and objectives are very diverse. Otherwise, it is essential to rank the overall buying factors and the aircraft-specific selection criteria [4]. Reference [6] shows Dozic \& Kalić used the Analytic Hierarchy Process (AHP) as one of the methods to rank and prioritize the key decision criteria in solving the aircraft type selection problem. The Analytic Hierarchy Process (AHP) method is useful when the decision maker was not able to make rankings and when the pairwise comparison is available [7]. By effectively selecting the most suitable aircraft type in selected routes, expectedly it could help the company's performance in maintaining its existing router and when opening a new route, to be more cost efficient and gain more profit. planning process are unique depending on each situation. It

This study focuses on the fleet planning topic, especially the aircraft selection, which is one of the main long-term strategic decision for an airline company that has a great impact on the company's financial condition. This study analyzes the fleet planning decision of the national flag carrier of Indonesia, especially the aircraft selection decision for several known high-frequency domestic route network. The fleet planning decision that meets the market's condition and airline's condition helps the company's performance in selecting the aircraft opening a new route, which is more cost efficient and expectedly could gain profit from the new route opening. By using the combination of Focus Group Discussion (FGD) and Analytic Hierarchy Process (AHP) methods in selecting the most suitable aircraft type, 6 (six) criteria and 4 (four) aircraft type alternatives were defined.

Based on the FGD result, the 6 (six) important criteria in selecting the most suitable aircraft are the (Maximum Take Off Weight (MTOW), Cost per Available Seat Kilometer (CASK), operational performance, delivery time, fleet commonality, and additional benefits. Based on the FGD results too, there are 4 (four) alternative aircraft types (B737-800NG, B737-8MAX, CRJ1000, and A330-300) that are suitable for those routes were defined. The result shows that the most suitable aircraft for high-frequency domestic routes is B737-800NG, which rank first in fleet commonality, operational performance, and delivery time. Then followed by B737-8MAX, A330-300, and CRJ1000. Both types of Boeing 737 family shows a lower total Cost per Available Seat Kilometer (CASK) compared to others. Even though B737-8MAX rank first in CASK and Additional Benefit criteria, but the rank dropped due to Operational Performances and Delivery Time criteria. Other than that, even though A330-300 rank first in Maximum Take Off Weight (MTOW) criteria, but MTOW is the least criteria that are considered in choosing the best aircraft type.

This paper is organized into 5 (five) main sections: Section 1 describes the research in general. Section 2 describes the theories related to airline business model and fleet planning. Section 3 describes the methodology of the research. Section 4 discusses the result and findings of the research. Lastly, Section 5 presents a summary of the research, managerial implications, limitations, then some recommendations for future research.

\section{LITERATURE REVIEW}

This chapter presents some theories related to fleet planning and some decision tools that are used to help in doing the planning decision.

\section{A. Fleet Planning}

One of the success factors in an airline is by matching both supplies and demand tightly to each other [8]. The most important airline planning process is mostly categorized into 3 categories, which are fleet planning, route planning, and schedule development. Fleet planning includes the fleet type to acquire, the time, and a number of the fleet. Route planning includes choosing the route destination that is 
profitable and availability constraints. Schedule development includes the frequency number, the times of each route that the flights should be operated, also operational and fleet limitations [5].

Table I. List of Related Studies: Fleet Planning Methods in the Airline Industry

\begin{tabular}{|l|l|l|l|}
\hline Author & Focus of Study & Method & Result \\
\hline Wang (2014) & Airline fleet composition & $\begin{array}{l}\text { Linear } \\
\text { Programming }\end{array}$ & $\begin{array}{l}\text { The numerical example was conducted under multi-Hubs \& Spoke network in } \\
\text { order to verify the feasibility and effectiveness of the proposed model. It is } \\
\text { necessary to figure out that the resulting solution to the fleet composition } \\
\text { under predicted operation environment often slightly different from the real } \\
\text { one due to the regardless of backups for the airline's fleet capacity. }\end{array}$ \\
\hline $\begin{array}{l}\text { Dozic \& } \\
\text { Kalic (2015a) }\end{array}$ & $\begin{array}{l}\text { Aircraft type selection } \\
\text { decision }\end{array}$ & $\begin{array}{l}\text { Multiple Criteria } \\
\text { Decision Making } \\
\text { (AHP and ESM) }\end{array}$ & $\begin{array}{l}\text { Both the Analytic Hierarchy Process (AHP) and Even Swap Method (ESM) } \\
\text { method can be used to solve the aircraft type selection problem. Both } \\
\text { methodologies could use quantitative and qualitative data. ESM is suitable for } \\
\text { cases that bave complete data dan can rank all alternatives across selected } \\
\text { criteria. Otherwise, AHP can be used when decision maker not able to make } \\
\text { rankings and when only the pairwise comparison is available. }\end{array}$ \\
\hline $\begin{array}{l}\text { Repko et al. } \\
\text { (2016) }\end{array}$ & $\begin{array}{l}\text { Airline fleet planning } \\
\text { problem }\end{array}$ & $\begin{array}{l}\text { Mixed-Integer } \\
\text { Linear } \\
\text { Programming }\end{array}$ & $\begin{array}{l}\text { The proposed scentario tree approach can provide flexible multi-period airline } \\
\text { fleet plans, which are more robust to future demand scenarios than fleet } \\
\text { solutions obtained using the traditional approach of considering a single } \\
\text { deterministic demand evolution scenario. }\end{array}$ \\
\hline $\begin{array}{l}\text { Carreira et al. } \\
\text { (2017) }\end{array}$ & $\begin{array}{l}\text { Long-hanl fleet renovation } \\
\text { to meet passenger demand } \\
\text { between Portugal - Brazil }\end{array}$ & $\begin{array}{l}\text { Two-stage } \\
\text { stochastic integer } \\
\text { program }\end{array}$ & $\begin{array}{l}\text { TAP should rearrange its fleet, depending on its available resources and } \\
\text { considering the lease of aircraft as an option since it allows the carrier to deal } \\
\text { with demand uncertainty, rather than purchasing a new aircraft. }\end{array}$ \\
\hline
\end{tabular}

Fleet planning is the process when an airline acquires and manages its appropriate fleet capacity to meet the market's demand over a variety of time period, in order to maximize the company's wealth [4]. The fleet planning for the airline industry is not different from other industries' planning activity, which is related to complexity, dilemmas, and uncertainty [4]. Because of its complexity, that is why an airline needs to consider many different factors, like the financial condition, the performances of the aircraft, the market evaluation, fleet economies, fleet commonality, and other aspects [6]. The main purpose of fleet planning is to get the best fleet combination and the best fleet type, which could serve a specific market demand [4].

Reference [4] shows that to make a good fleet planning, there are 3 (three) basic golden rules, which are adaptability, flexibility, and continuity. Adaptability is related to the fleet size and appeal, the appropriateness of fleet economic and performance delivery. Flexibility is related to the payload versatility of fleet design offering, the operational flexibility of fleet family offering, easiness factor of capacity's phase in or out. Then, the continuity is related to product line coherence.

In achieving its goal, an airline better to use an appropriate approach in their fleet planning process. The fleet selection on a defined route network becomes an important element that has a direct impact on the increase of airline's profitability and cost reduction [8]. Fleet planning decision in one airline company mostly depends on an evaluation of its economic and financial performance [5].

\section{B. $\quad$ Fleet Planning Model}

In determining its fleet planning model, an airline could try various models to get the appropriate fleet planning as needed. Table I shows the summary of existing studies on airline fleet planning method, including the focus of the study and the result of the study.

Based on those previous study, in helping them to decide its fleet planning, an airline could use the mathematical or quantitative method, such as linear programming and integer programming, or even use the combination of quantitative and qualitative method, such as Analytic Hierarchy Process [6].

In linear programming, the model contains a linear correlation, which related to the company's decision, resource constraints, and given objective [9]. Reference [9] shows that there are 3 (three) main steps in applying linear programming. First is identifying the problem that needs to be solved by linear programming. Second is formulating the unstructured problem as a mathematical model. The last is solving the model by using mathematical techniques. The linear programming has similar characteristics, such as there is an objective function that needs to be minimized or maximized, there is a linearity among the objective level and all constraint relationships, there are decision variables, which is for measuring the activity level, and there is a set of constraint [9]. In airline industry practices, one of the linear programming' weaknesses is that this model is deterministic, while air travel's demand is stochastic [10].

Integer programming models are mainly divided into 3 (three) basic types [9]. First, the total integer model, which requiring entire decision variables to have the integer solution values. Second, the $0-1$ integer model, which entire decision variables have zero or one integer values. Third, the mixed integer model, which only requires some of the decision variables (not the entire) to have integer solutions. In previous linear and integer programming models, a single objective was either minimized or maximized. In fact, an organization usually has more than 1 (one) objective or multiple criteria, which is beyond the profit or cost only [9].

\section{Multiple Criteria Decision Making}

Multiple Criteria Decision Making (MCDM) is one of the most well-known branches of decision-making. It is divided

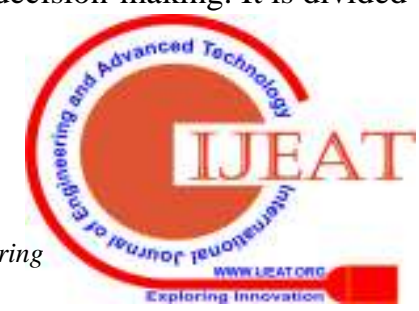


into Multi-Objective Decision Making (MODM), which concentrates on the problem with continuous decision space, and Multi-Attribute Decision Making (MADM), which concentrates on the problem with discrete decision space [11].

Reference [9] shows that there are 3 (three) main tools to solve the multiple objective problems; goal programming, scoring model, Analytic Hierarchy Process (AHP). First, goal programming resembles a linear programming model, which has decision variables, objective function, and constraints. The differences are the model includes multiple objectives, rather than a single objective. Second, the Analytical Hierarchy Process (AHP), which is a method that ranking the entire decision alternatives and selecting the best one given multiple criteria. Third, the scoring models resembles the AHP method. The difference is that it uses simpler mathematics.

Reference [11] shows that each MCDM problem is associated with multiple attributes, which also referred to as "goals" or "decision criteria." These attributes represent different dimensions from which the alternatives can be viewed. There are several most widely used methods to solve multiple criteria problem, such as the ELECTRE, the TOPSIS, the weighted product model (WPM), the weighted sum model (WSM), the analytic hierarchy process (AHP), the revised AHP.

\section{Analytic Hierarchy Process}

AHP decomposes a complex MCDM problem into a system of hierarchies [11]. AHP is a systematic approach developed to give decision-making based on experience, intuition, and heuristics the structure of well-defined methodology derived [12]. AHP is a multi-criteria decisionmaking approach that implies dividing the problem into a hierarchy of issues. AHP considers a set of chosen criteria and set of alternatives among which the best solution to be found regarding the weights of criteria and alternatives [6].

AHP uses a combination of quantitative and qualitative data, which later would be translated into numbers [6]. There are several steps that need to be followed in the AHP method, which is develop a model for decision by building hierarchy (structure of the problem) for the decision, derive priorities or weights for the criteria, derive local priorities or preferences for the alternatives, derive overall priorities (model synthesis), perform sensitivity analysis, and the last step is making a final decision [13].

Reference [9] shows there are 3 (three) main tools to solve the multiple objective problems, which are goal programming, analytical hierarchy process, and scoring models. First, goal programming resembles a linear programming model, which has decision variables, objective function, and constraints. The differences in the model include multiple objectives, rather than a single objective. Second is the Analytical Hierarchy Process (AHP), which is a method that ranking the entire decision alternatives and scoring models resemble the AHP method. The difference is that it uses simpler mathematics.

AHP uses a combination of quantitative and qualitative data, which later would be translated into numbers [6]. Reference [13] shows that there are several steps that need selecting the best one given multiple criteria. Third, the

to be followed in the AHP method, which is develop a model for decision by building hierarchy (structure of the problem) for the decision, derive priorities or weights for the criteria, derive local priorities or preferences for the alternatives, derive overall priorities (model synthesis), perform sensitivity analysis, and the last step is making a final decision.

\section{METHODOLOGY}

The research uses both combinations of quantitative and qualitative method, like Focus Group Discussion (FGD) and Analytic Hierarchy Process (AHP), to help in answering the research objectives. After defining the research objective, then the author did a literature review on related studies and cases. The second step was getting some information related with fleet planning, aircraft type selection, Focus Group Discussion (FGD) method, and Analytic Hierarchy Process (AHP) method, then choosing and selecting some experts that have knowledge on the research matter. After that, gather all expert in an FGD forum by paralleling implement the AHP method. Then, the result of the FGD was analyzed to get some conclusion and recommendations.

The data gathered from 2 (two) main sources, which are the primary and secondary source. The primary data gathered by conducting Focus Group Discussion, with the participation of some national flag carrier of Indonesia's key employees from Corporate Planning Unit, Network Planning Unit, Asset Management Unit, and Procurement Unit. By doing the focus group discussion approach, it would help the Company to identify and understand the better view of the case, related to the current practice of fleet planning, the fleet planning problem, and determine the key factor prioritization in the national flag carrier of Indonesia.

The secondary data gathered from either internal and external sources. First, secondary data from the Corporate Planning Unit, to get the historical and projected fleet performance data, which could help in analyzing the case. Second, some theories related to fleet planning, fleet planning models, Multiple Criteria Decision Making (MCDM), and Analytic Hierarchy Process (AHP) for better understanding of the research topic. The last, other related theories, such as airline case study, fleet planning case study, and some information related to it from mass media and the Internet. For example, the Center for Aviation/ CAPA analysis and other airlines market data. The output of the research formed in data analysis, conclusion, and recommendation.

In this study, the author uses one of multi-criteria decision making, which is the Analytic Hierarchy Process (AHP) method that widely uses and remains one of the most popular multiple criteria decision-making methods [14]. Besides this AHP offers a simple method, which does not require a complex and complicated mathematical operation, this method usually used by professionals. In comparison, AHP has been criticized from several perspectives. The first reason is that its ratio scale is sometimes inaccurate. The second reason is its rank reversal. In several scenarios, when 
a new alternative is added, the previous alternative ranking resulted by AHP may change. Despite its weaknesses, the AHP approach is still used by many individuals and businesses because of its ease of use [12].

After determining the criteria and alternatives at the beginning session of FGD, then the data could be constructed into the decision hierarchy model, which could help participants to understand the linkage between alternatives, criteria, which could affect the main goal or objectives. Then, the next step is setting up the pairwise comparison matrix and comparing the importance of each criterion and alternatives. After collecting all judgments or preferences from participants, it is very important to check its consistency. Since the numeric values are derived from the individual's subjective judgment or preferences, then there were some inconsistencies that are impossible to avoid in judgment's final matrix [13]. AHP calculates the Consistency Ratio (CR) by comparing the Consistency Index (CI) with Random Index (RI). Based on Saaty and Vargas, the consistency ratio (CR) must be less than 0.1 for the data to be accepted in the AHP analysis [15].

\section{RESULT AND FINDINGS}

In determining criteria for choosing the best aircraft type, 4 (four) experts from respective units, which is from Network Management (specifically route planning management), Corporate Planning, Acquisition and Aircraft Management (specifically Fleet Performance and Optimization), and Business Performance Management (previously from Procurement division) were chosen to do the focus group discussion. The Fig. 1 shows that based on Focus Group Discussion (FGD) result, there are 6 (six) criteria defined; Maximum Take Off Weight, Cost per Available Seat Kilometer, Operational Performances, Delivery Time, Fleet Commonality, and Additional Benefits. Then, based on the FGD result too, some aircraft type alternatives, which focus on 5 (five) highest frequency domestic routes (Surabaya, Denpasar, Medan, Yogyakarta, and Semarang), were also defined; B737-800NG, B7378MAX, CRJ1000, A330-300.

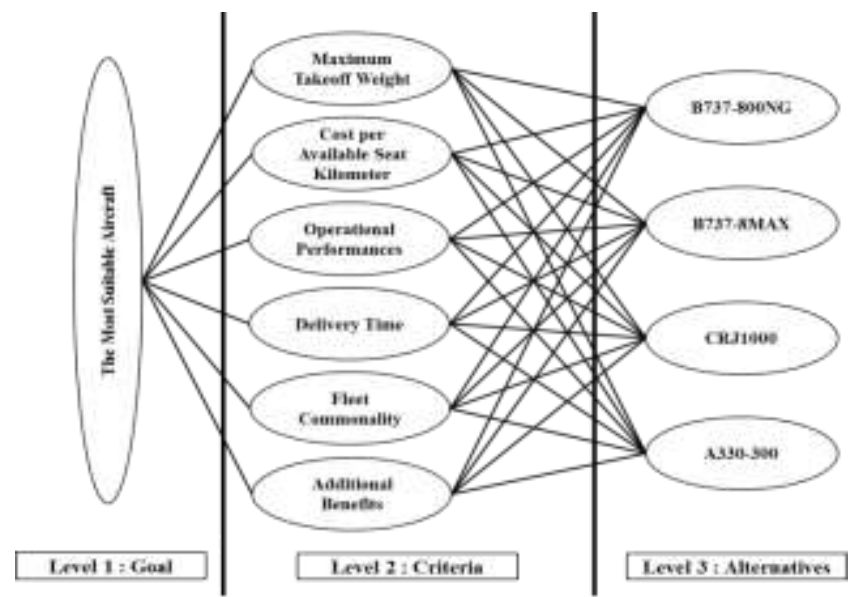

Figure 1. Decision Hierarchy for Getting the Most Suitable Aircraft

From the Table II below, based on the pairwise comparison matrix for the first level result, the Cost per Available Seat Kilometer (CASK) was prioritized as the number one priority criteria in choosing the most suitable aircraft type. Then followed by the fleet commonality, operational performances, delivery time, additional benefits, and Maximum Takeoff Weight (MTOW).

CASK becomes the most important criteria, because the lower number its CASK, the more profitable and efficient an airline is. In CASK, purchasing or leasing cost, and maintenance cost is included in the total cost. After that, the fleet commonality also considered as an important factor, because the more simplified the aircraft type in fleet profile, it could contribute in lowering the CASK, especially affecting the crew and maintenance cost.

The third important criteria are operational performances. It becomes important because it could also affect the CASK. These operational performances include the fuel burn, flight range, reliability, comfortability (either from pilot and passenger side), and aircraft stability. The fourth criteria are the delivery time. This delivery time related to the availability of the aircraft (in the market and the production time), when an airline needs a specific aircraft to support their operation. It could also relate with lessor or manufacturer's ability to fulfill airline's need for production, because as we know that the process in making 1 (one) aircraft takes a lot of time.

The fifth criteria to be considered is additional benefits or any other benefit from lessor or manufacturers for an airline that could affect the airline's decision in purchasing the aircraft. It could also relate to payment conditions and maintenance condition from the lessor or manufacturers. The last criteria are the Maximum Take Off Weight (MTOW) or usually called gross weight. From the FGD result, MTOW is less important for the domestic route, which mainly uses narrow-body aircraft. The 5 airports in this study are also considered very good and able to accommodate narrow-body aircraft. Otherwise, still, an important consideration when buying an aircraft (choose the one that has bigger MTOW).

In Table III, it shows that the A330-300 is preferable than other types, in terms of maximum take-off weight concern. After that, followed by the B737-8MAX, B737-800NG, and CRJ1000. Since A330-300 is a wide-body aircraft, expectedly it has the biggest MTOW, compared to narrowbody aircraft. The MTOW for A330-300 is 212,000 kilograms, while B737-800NG is 79,017 kilograms, B737$8 \mathrm{MAX}$ is 82,200 kilograms, and CRJ1000 is 41,640 kilograms, which is around one-fifth of A330-300 and the least preferable in terms of MTOW.

In Table IV, it shows that B737-8MAX is preferable than other types of aircraft, in terms of CASK. After that, the rank is followed by B737-800NG, A330-300, and CRJ1000. From the result, Boeing 737 family (both B737-800NG and B737-8MAX) has lower CASK, especially B737-8MAX, which is the newer generation of B737-800NG. Based on historical performance, the narrow-body aircraft normally has a lower CASK compared to wide-body aircraft, due to its smaller load and a smaller number of crews needed. In addition, for the national flag carrier of Indonesia's case, the since the Boeing 737 aircraft family dominating most of the

Published By:

Blue Eyes Intelligence Engineering

\& Sciences Publication 
International Conference on Recents Advancements in Engineering and Technology (ICRAET-18) |15th and 16th March 2019|Siddhartha Institute of Technology \& Sciences, Telangana, India.

fleet composition, the maintenance and crew cost can be efficiently managed and divided evenly per aircraft. On the other hand, even though CRJ1000 is also categorized as a narrow-body aircraft, it has the highest CASK compared to other aircraft types. Several reasons were because of its high maintenance and crew cost to manage a small number of aircraft (18 aircraft), then its smaller number of seats (96 seats per aircraft), which affects the aircraft cost per unit. The CRJ1000 is commonly preferable for a market that has a high yield with a low density (for the secondary market).

In Table V, it shows that the A330-200 is preferable than other types, in terms of operational performances concern. After that, followed by the A330-300, B737-8MAX, and CRJ1000. Based on historical data, B737-800NG gives a more stable performance than other types.

B737-8MAX supposedly has better operational performance, compared to B737-800NG. However, based on historical 2 (two) major aircraft accident in Indonesia and Ethiopia, the aircraft's reliability becomes questionable. On the other hand, even though there is no accident happened, CRJ1000 becomes the least preferable aircraft because of its performance history that has lower dispatch reliability due to minor maintenance, such as the needs of spare part changing. In fact, the number of spare part supplier is very limited and recently the Company bought spare part directly to Bombardier (the CRJ1000's manufacturer).

In Table VI, it shows that the B737-800NG is preferable than other types, in terms of delivery time concern. After that, the rank is followed by A330-300, B737-8MAX, and CRJ1000. Considering the availability of aircraft in the market, B737-800NG is easier to find, especially when most of the airline companies owned B737-800NG, then continued with the A330-300. Since B737-8MAX is categorized as a newer type, which is expected could replace the B737-8NG existence in the market, it is mostly still in production and needs years to finish the production. In addition, in the last rank, CRJ1000's availability in the market is very rare and only a few companies owned the aircraft type.

In Table VII, it shows that B737-800NG is preferable than other types of aircraft, in terms of fleet commonality concern. After that, followed by the B737-8MAX, A330300, and CRJ1000. Currently, GA's fleet was dominated by the B737 family; 73 aircraft of B737-800NG and 1 aircraft of B737-8MAX. After that, the A330-300 is the highest number of wide-body aircraft in the national flag carrier of Indonesia's fleet composition.

In Table VIII, it shows that B737-8MAX is preferable than another type of aircraft, in terms of additional benefits concern. After that, followed by B737-800NG, A330-300, and CRJ1000. Considering the current safety issue caused by 2 (two) fatal crashes, which made authorities in several countries (such as U.S., Europe, China, and Indonesia) issuing the grounded notification for B737-8MAX [16], Boeing has a lower bargaining power compared to many airlines company. In addition, some of its customers also start to cancel the order of the B737-8MAX, which is worth around \$ 6 billion. Those grounding policy and aircraft's cancellation could affect Boeing's overall business. Based on that fact and assumption, expectedly Boeing will give a lot of gimmick and any additional benefits to its customer, to maintain their existing customer and their reputation.

Table II. The Pairwise Comparison Matrix for the First Level

\begin{tabular}{|c|c|c|c|c|c|c|c|c|}
\hline & MTOW & CASK & $\begin{array}{l}\text { Operational } \\
\text { Performance }\end{array}$ & $\begin{array}{c}\text { Delivery } \\
\text { Time }\end{array}$ & $\begin{array}{c}\text { Fleet } \\
\text { Commonality }\end{array}$ & $\begin{array}{c}\text { Additional } \\
\text { Benefits }\end{array}$ & Priority & Rank \\
\hline MT0W & 1.000 & 0.143 & 0.250 & 0.333 & 0.125 & 0.500 & 0.035 & 6 \\
\hline CASK & 7.000 & 1.000 & 3.000 & 3.000 & 1.000 & 7.000 & 0.321 & 1 \\
\hline $\begin{array}{l}\text { Operational } \\
\text { Performance }\end{array}$ & 4.000 & 0.333 & 1.000 & 5.000 & 1.000 & 5.000 & 0.212 & 3 \\
\hline Delivery Time & 3.000 & 0.333 & 0.200 & 1,000 & 0.167 & 5.000 & 0.099 & 4 \\
\hline Fleet Commonality & 8.000 & 1.000 & 1.000 & 6.000 & 1.000 & 5.000 & 0.287 & 2 \\
\hline Additional Benefits & 2.000 & 0.143 & 0.200 & 0.200 & 0.200 & 1.000 & 0.046 & 5 \\
\hline \multicolumn{2}{|c|}{$\lambda_{\max }=6.5252$} & \multicolumn{2}{|c|}{$\mathrm{Cl}=0.1050$} & \multicolumn{3}{|c|}{$C R=0.0847$} & & \\
\hline
\end{tabular}

Table III. The Domination Measure of an Aircraft over Another with Respect to Maximum Takeoff Weight

\begin{tabular}{|l|c|c|c|c|c|c|}
\hline \multicolumn{1}{|c|}{ MTOW } & B737-800NG & B737-8MAX & CRJ1000 & A330-300 & Priority & Rank \\
\hline B737-800NG & 1.000 & 0.500 & 5.000 & 0.200 & 0.153 & 3 \\
\hline B737-8MAX & 2.000 & 1.000 & 4.000 & 0.250 & 0.200 & 2 \\
\hline CRJ1000 & 0.200 & 0.250 & 1.000 & 0.125 & 0.051 & 4 \\
\hline A330-300 & 5.000 & 4.000 & 8.000 & 1.000 & 0.596 & 1 \\
\hline \multicolumn{7}{|c|}{$C I=0.0621$} \\
$\lambda_{\max }=4.1863$
\end{tabular}


Table IV. The Domination Measure of an Aircraft over Another with Respect to Cost per Available Seat Kilometer

\begin{tabular}{|l|c|c|c|c|c|c|}
\hline \multicolumn{1}{|c|}{ CASK } & B737-800NG & B737-8MAX & CRJ1000 & A330-300 & Priority & Rank \\
\hline B737-800NG & 1.000 & 0.500 & 5.000 & 3.000 & 0.309 & 2 \\
\hline B737-8MAX & 2.000 & 1.000 & 6.000 & 4.000 & 0.492 & 1 \\
\hline CRJ1000 & 0.200 & 0.167 & 1.000 & 0.333 & 0.063 & 4 \\
\hline A330-300 & 0.333 & 0.250 & 3.000 & 1.000 & 0.136 & 3 \\
\hline \multicolumn{7}{|c|}{$C l=0.0265$} \\
\hline
\end{tabular}

Table V. The Domination Measure of an Aircraft over Another with Respect to Operational Performances

\begin{tabular}{|l|c|c|c|c|c|c|}
\hline Operational Performances & B737-800NG & B737-8MAX & CRJ1000 & A330-300 & Priority & Rank \\
\hline B737-800NG & 1.000 & 5.000 & 8.000 & 3.000 & 0.584 & 1 \\
\hline B737-8MAX & 0.200 & 1.000 & 4.000 & 1.000 & 0.171 & 3 \\
\hline CRJ1000 & 0.125 & 0.250 & 1.000 & 0.250 & 0.054 & 4 \\
\hline A330-300 & 0.333 & 1.000 & 4.000 & 1.000 & 0.191 & 2 \\
\hline \multicolumn{7}{|c|}{$C l=0.0268$} \\
\hline
\end{tabular}

Table VI. The Domination Measure of an Aircraft over Another with Respect to Delivery Time

\begin{tabular}{|l|c|c|c|c|c|c|}
\hline Delivery Time & B737-800NG & B737-8MAX & CRJ1000 & A330-300 & Priority & Rank \\
\hline B737-800NG & 1.000 & 7.000 & 8.000 & 4.000 & 0.623 & 1 \\
\hline B737-8MAX & 0.143 & 1.000 & 3.000 & 0.333 & 0.107 & 3 \\
\hline CRJ1000 & 0.125 & 0.333 & 1.000 & 0.250 & 0.055 & 4 \\
\hline A330-300 & 0.250 & 3.000 & 4.000 & 1.000 & 0.215 & 2 \\
\hline \multicolumn{7}{|c|}{$C l=0.0513$} \\
\hline
\end{tabular}

After getting all of the priorities calculation from criteria and alternatives above, then the overall priority result is shown in Table IX. The most suitable aircraft type for high frequencies domestic routes is $\mathrm{B} 737-800 \mathrm{NG}$, which rank first in fleet commonality, operational performance, and delivery time. Then followed by B737-8MAX, A330-300, and the least preferable is CRJ100. Both types of Boeing 737 family shows a lower total Cost per Available Seat Kilometer (CASK) compared to others. Even though B7378MAX rank first in CASK and Additional Benefit criteria, but the rank dropped due to Operational Performances and Delivery Time criteria. Other than that, even though A330300 rank first in Maximum Take Off Weight (MTOW) criteria, but MTOW is the least criteria that are considered in choosing the best aircraft type.

\section{CONCLUSION}

This study aims to provide an illustration of aircraft type selection problem solving for known routes, especially the high-frequency domestic routes, which expectedly could help other airline companies in considering more careful planning in the future. In selecting the most suitable aircraft for high-frequency domestic routes, the Cost per Available Seat Kilometer (CASK) was prioritized as the number one priority criteria. Then followed by the fleet commonality, operational performances, delivery time, additional benefits, and Maximum Takeoff Weight (MTOW). From 4 (four) alternative aircraft types, B737-800NG ranks first in fleet commonality, operational performance, and delivery time criteria. After that, followed by the B737-8MAX, A330-300, and CRJ1000. From the result, it shows that both types of Boeing 737 family show a lower total Cost per Available Seat Kilometer (CASK) compared to other aircraft. In addition, even though B737-8MAX ranks first in CASK and Additional Benefit criteria, but its rank dropped due to the result of Operational Performances and Delivery Time criteria.

Based on the discussion above, it is better to utilize B737$800 \mathrm{NG}$ for existing and new similar high-frequency domestic routes. By choosing B737-800NG, expectedly it could give a great impact on the company's financial condition, which is more cost efficient and could increase 
the Company's profit. As a recommendation, it is also better to combine the use of A330-300 (wide-body aircraft) in the operation, especially for the use in a peak hour and peak season. By using a wide-body aircraft, it could help the Company to overcome the over-demand and avoid its customer to shift and move to other competitors. Then, considering increasing the use of B737-8MAX (the next generation of B737-800NG) in the future, by considering several important points, such as its availability and readiness in the market, the safety assurance and a guarantee from Boeing, market's trust on Boeing's B737-8MAX and Boeing's attractive price quotation and additional benefits' offering.

In addition, this study has a limitation due to the time constraint in analyzing all domestic routes from/to Soekarno Hatta International Airport. In this study, we only able to analyze 5 (five) high-frequency domestic routes (Jakarta Denpasar, Jakarta - Medan, Jakarta - Semarang, Jakarta Surabaya, Jakarta - Yogyakarta) by excluding the transit flight to international destinations. Furthermore, we cannot further analyze the factors affecting aircraft type selection in our study. We hope to address these limitations in our future research.

\section{REFERENCES}

1. Centre for Aviation. (2016, June 2). CAPA Global Airline Financial Outlook. Available: https://centreforaviation.com/analysis/reports/leaderglobal-airline-financial-outlook-283799

2. IATA. (2018, October 24) IATA Forecast Predicts 8.2 billion Air Travelers in 2037. Available: https://www.iata.org/pressroom/pr/Pages/2018-10-2402.aspx

3. G. Gumelar. (2018, February 1). Indonesia Dikunjungi 14 Jutaan Turis Sepanjang 2017. Available: https://www.cnnindonesia.com/gayahidup/20180201163952-269-273237/indonesiadikunjungi-14-jutaan-turis-sepanjang-2017

4. P. Clark, Buying the big jets: Fleet planning for airlines (2nd ed.). Aldershot: Ashgate, 2007.

\section{AUTHORS PROFILE}

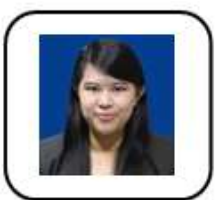

Astrid Kartika Born in 1990 in Jakarta Working in Airline Industries since 2013 until now. Starting her career as Enterprise Risk Management specialist/ analyst until 2016 and has been licensed as Certified Risk Management Professional in 2013. From 2016 until now, Astrid is assigned as a Business Analyst, specifically in charge in Business Process Management, Project Management, and Business Performance Monitoring. In 2010, Astrid obtained Bachelor of Management from Institut Teknologi Bandung, Indonesia, majoring in Marketing. Currently, Astrid is continuing her study as MM-MBA candidate in Universitas Indonesia, taking an MM-MBA dual degree program between Universitas Indonesia and I.A.E de Grenoble, Universite Grenoble Alpes, France.

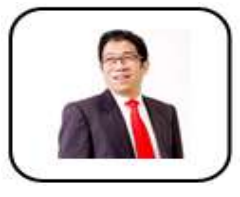

Alberto Daniel Hanani Born in 1965 in Jakarta. Appointed as a Managing Director at PT. Sarana Lindung Upaya since 2014, before previously served as President Commissioner at PT. Sarana Lindung Upaya. Alberto has obtained a Bachelor of Economics degree from the Universitas Indonesia, obtained an MBA at Imperial College, Science Technology \& Medicine -
Management School, and obtained a PhD Candidate at Imperial College, Science Technology \& Medicine - Management School. 